\title{
Notes on the vocalizations of Yellow-bellied Siskin (Carduelis xanthogastra)
}

Peter Boesman

In the following we briefly analyze and compare voice of the two races of Yellow-bellied Siskin (Carduelis xanthogastra). We also try to quantify the extent of any vocal differences using the criteria proposed by Tobias et al. (2010), as a support for taxonomic review. We have made use of sound recordings available on-line from Xeno Canto (XC).

A comparison of vocalizations per race, illustrated with sonograms:

S. x. xanthogastra (northern Andes S to NW Peru)

* continuous song
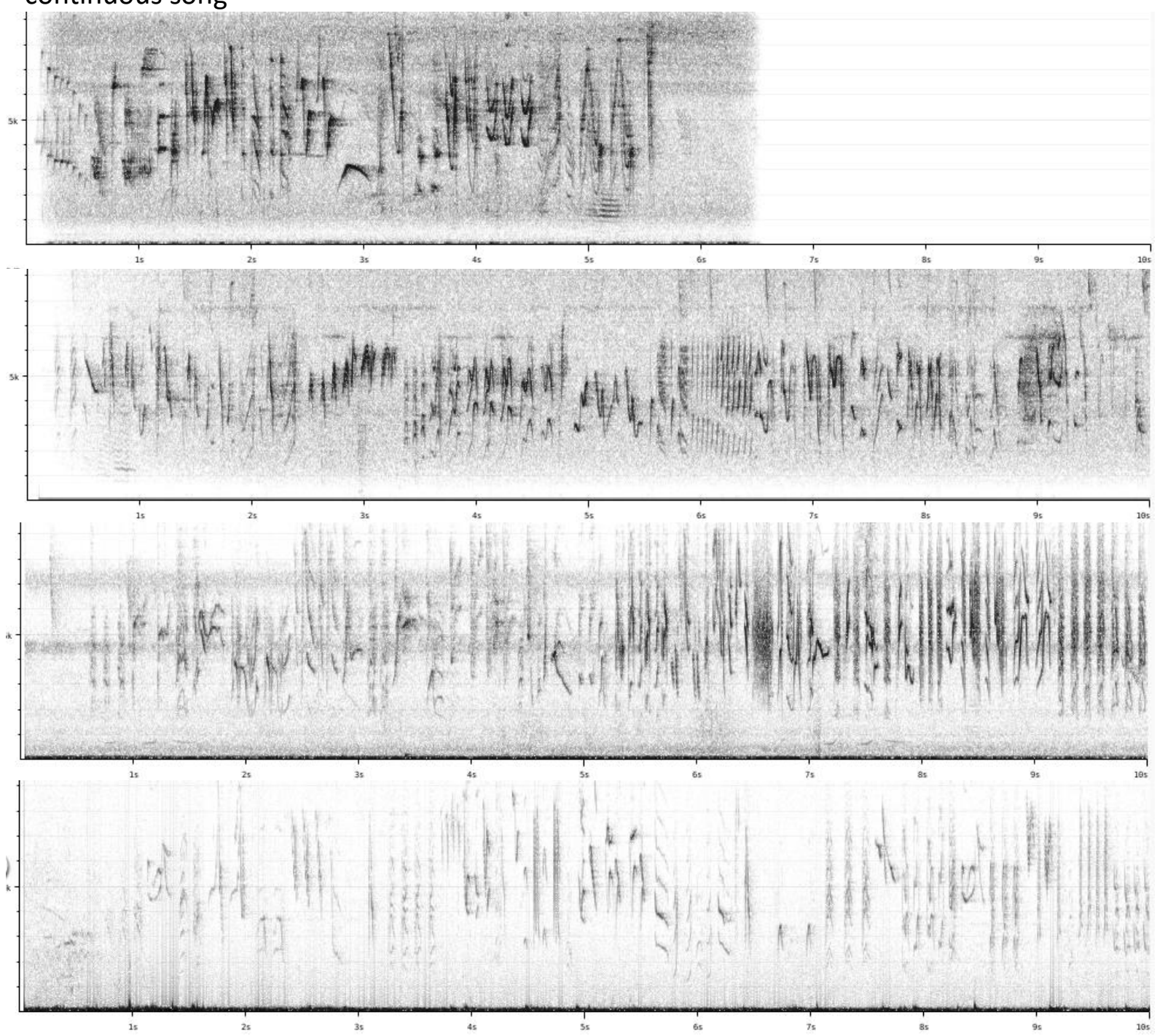


\section{HANDBOOK OF THE \\ BIRDSPF THE WORLD}

\section{ORNITHOLOGICAL NOTES}

* song strophes

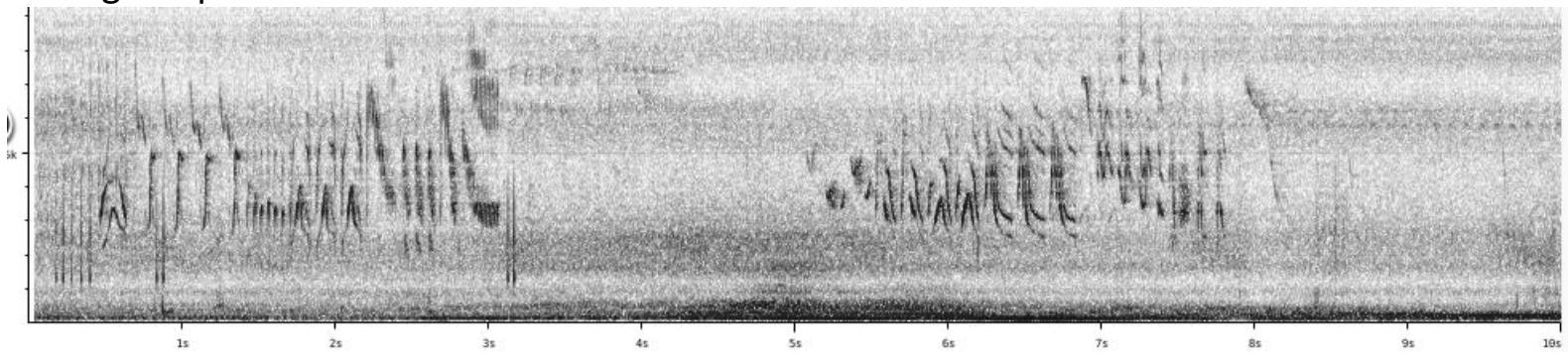

* 'short song'

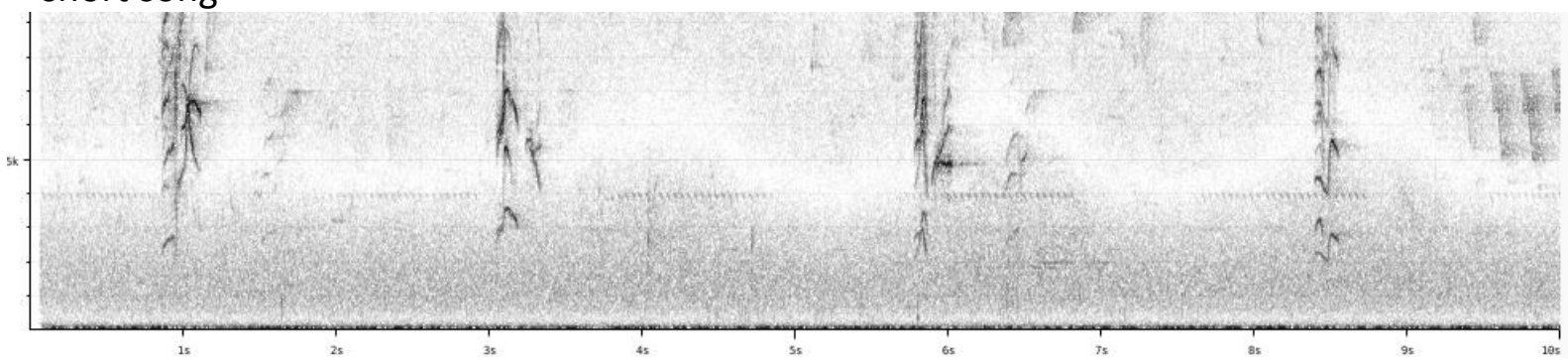

* call

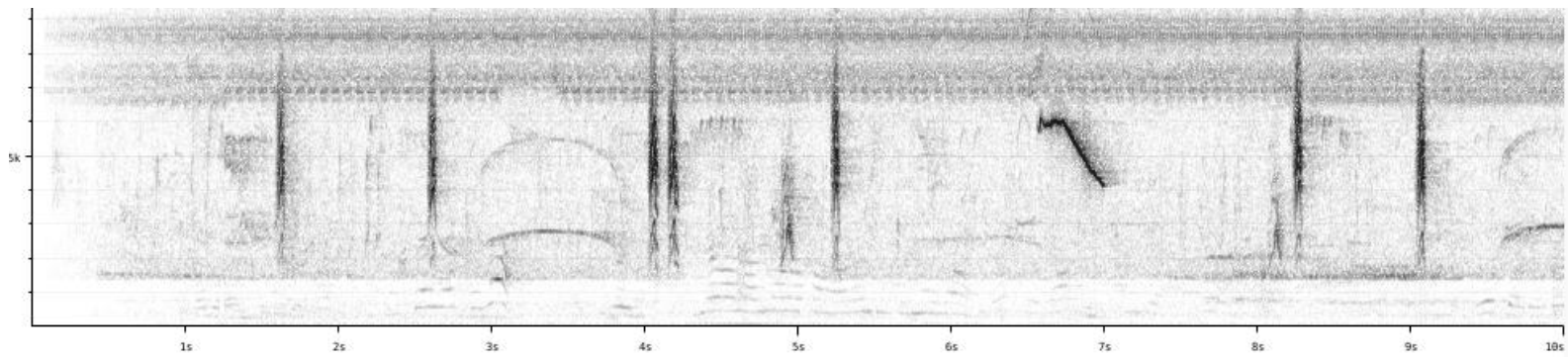

S. x. stejnegeri (extreme SE Peru and W Bolivia)

* continuous song

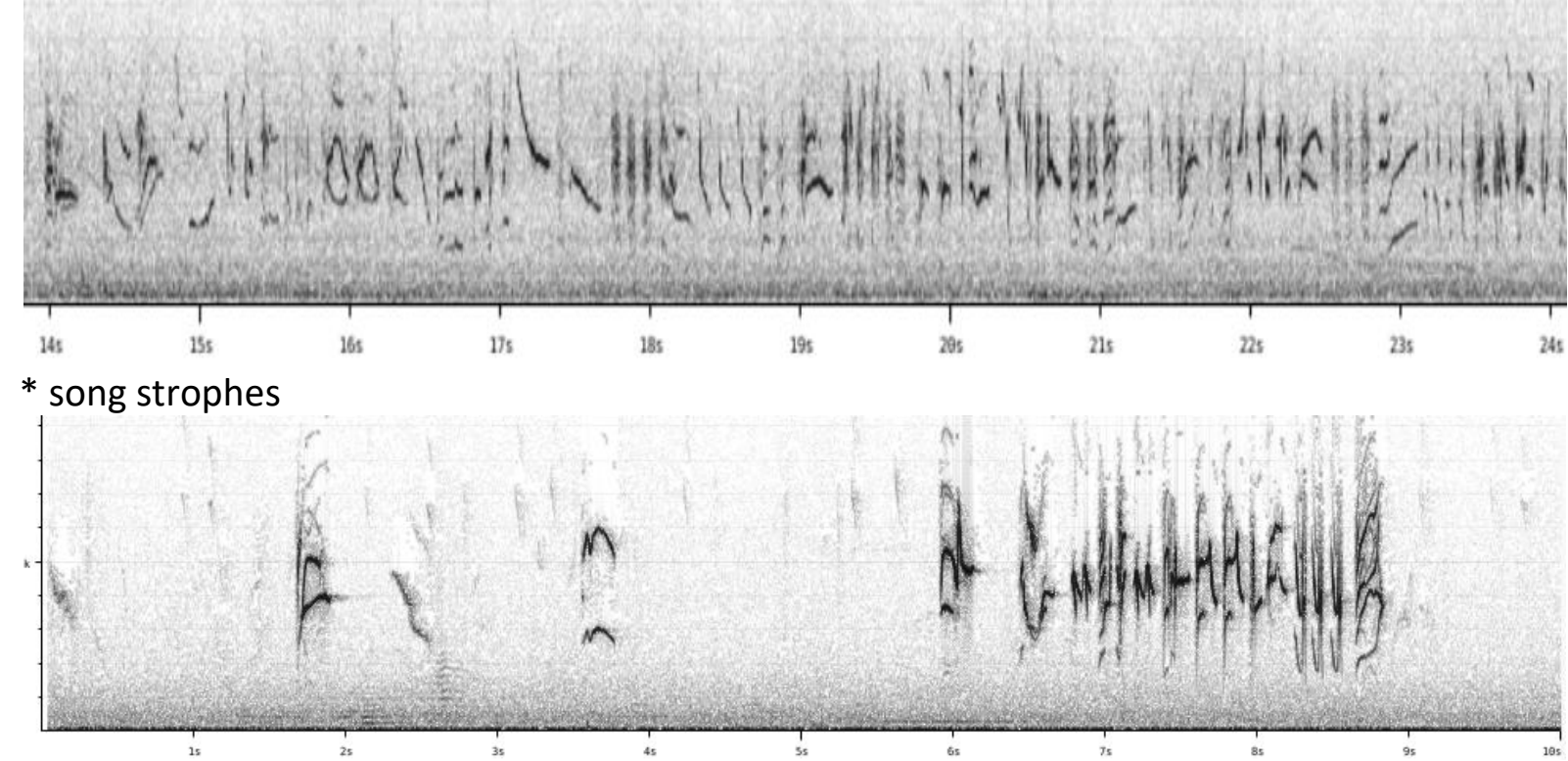



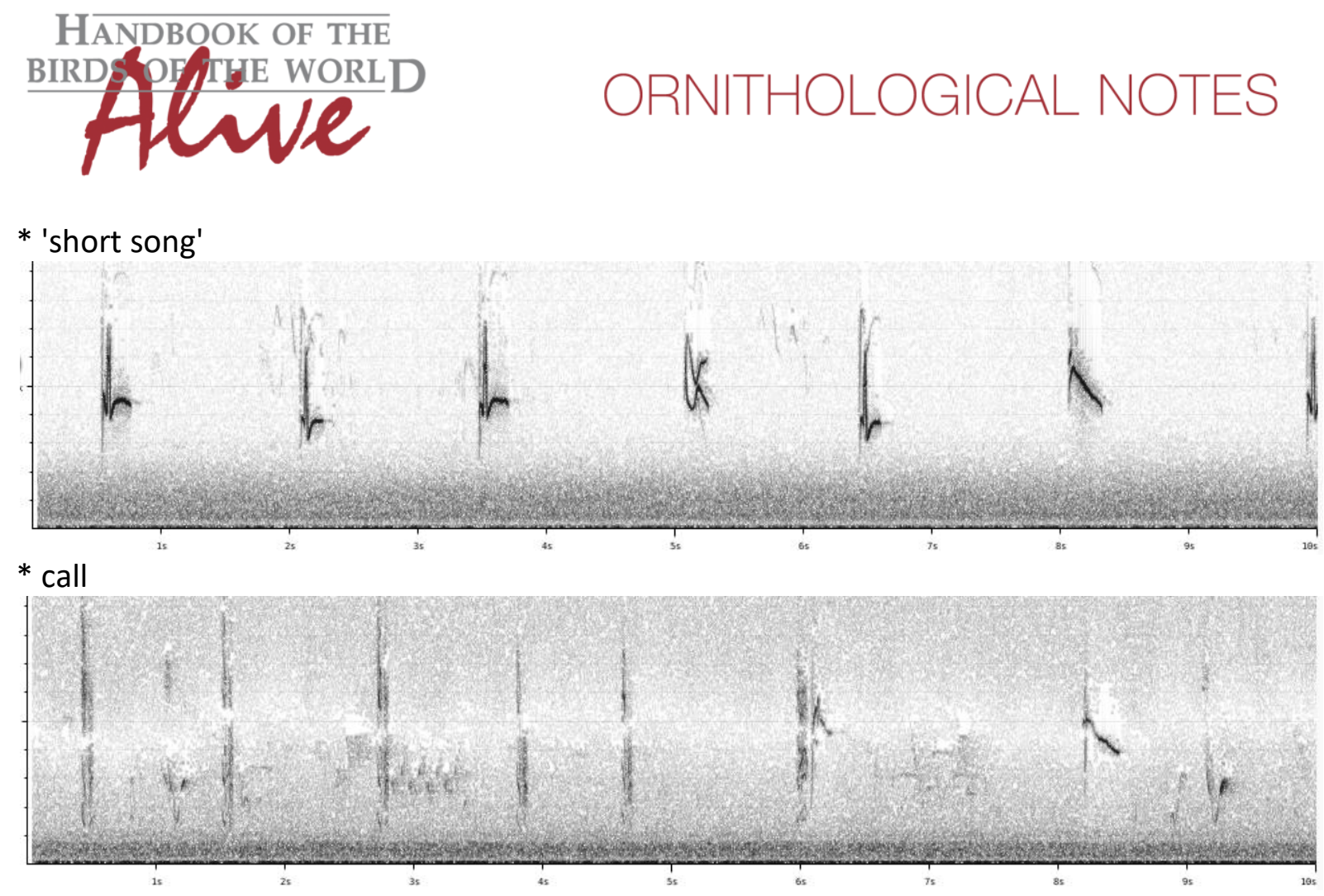

There are only few recordings available of race stejnegeri. Vocalizations are structurally similar to nominate. It would seem that stejnegeri more often utters a simple song of wellseparated notes, but nominate occasionally also utters such song. Full song is similar to nominate (and more recordings would be needed to prove any significant differences). Recordings of call notes are also too few to draw any conclusions, and at least some call notes are quite similar. Vocal differences thus seem to be rather minor.

This note was finalized on 7th October 2016, using sound recordings available on-line at that moment. We would like to thank in particular the sound recordists who placed their recordings for this species on XC: Nick Athanas, Peter Boesman, Sander Bot, Allen Chartier, Oswaldo Cortes, Fernand Deroussen, Olaf Jahn, Joe Klaiber, Nick Komar, Niels Krabbe, Dan Lane, Albert Lastukhin, Gabriel Leite, Mitch Lysinger, Oscar Marin Gomez, Sjoerd Mayer, Mike Nelson, Jonas Nilsson, Manuel Sanchez and Herman Van Oosten.

\section{References}

Tobias, J.A., Seddon, N., Spottiswoode, C.N., Pilgrim, J.D., Fishpool, L.D.C. \& Collar, N.J. (2010). Quantitative criteria for species delimitation. Ibis 152(4): 724-746.

\section{Recommended citation}

Boesman, P. (2016). Notes on the vocalizations of Yellow-bellied Siskin (Carduelis xanthogastra). HBW Alive Ornithological Note 437. In: Handbook of the Birds of the World Alive. Lynx Edicions, Barcelona. (retrieved from http://www.hbw.com/node/1284495 on 9 December 2016). 